\title{
Autoimmune Thyroid Disease Genes Identified in Non-Caucasians
}

\author{
Yoshihisa Ban $^{1}$, Yoshiyuki Ban ${ }^{2 *}$, Yoshio Ban ${ }^{1}$ \\ ${ }^{1}$ Ban Thyroid Clinic, Tokyo, Japan \\ ${ }^{2}$ Division of Diabetes, Metabolism, and Endocrinology, Department of Medicine, School of Medicine, Showa University, \\ Tokyo, Japan \\ Email: *yshyban@yahoo.co.jp
}

Received June 13, 2012; revised July 15, 2012; accepted August 19, 2012

\begin{abstract}
Autoimmune thyroid diseases (AITDs), including Graves' disease (GD) and Hashimoto's thyroiditis (HT), are among the commonest autoimmune disorders, affecting approximately $2 \%-5 \%$ of the population. Epidemiological data support strong genetic influences on the development of AITD. The identification of genes placing individuals at an increased risk for the development of AITD has been a slow process. However, over the last 20 years or so real progress has been made with the mapping of novel loci, via a number of different approaches. The first AITD gene discovered, Human Leucocyte Antigen (HLA)/Major Histocompatibility Complex (MHC), is associated with both GD and HT. Non-MHC genes that confer susceptibility to AITD can be classified into two groups: (1) immune-regulatory genes (e.g., CD40, CTLA-4, and PTPN22); (2) thyroid-specific genes-thyroglobulin and TSH receptor genes. These genes interact with environmental factors, such as infection, likely through epigenetic mechanisms to trigger disease. In this review, we will summarize the latest findings on AITD susceptibility genes in non-Caucasians.
\end{abstract}

Keywords: Gene; Thyroid; Autoimmunity; Association

\section{Introduction}

Autoimmune thyroid diseases (AITDs) are common autoimmune endocrine diseases [1], and according to one study, AITD are the commonest autoimmune diseases in the USA [2]. Even though the hallmark of AITD is infiltration of the thyroid with thyroid reactive lymphocytes, the end result are two clinically opposing syndromes: Hashimoto's thyroiditis (HT) manifesting by hypothyroidism and Graves' disease (GD) manifesting by hyperthyroidism. In HT, the lymphocytic infiltration of the thyroid gland leads to apoptosis of thyroid cells and hypothyroidism [3]. In contrast, in GD, the lymphocytic infiltration of the thyroid leads to activation of TSH receptor (TSHR)-reactive B cells that secrete TSHR-stimulating antibodies causing hyperthyroidism [4]. GD and HT are complex diseases, and their etiology involves both genetic and environmental influences [1]. Up until 15 years ago, the only known gene for AITD was HLA-DR3 haplotype (DRB1*03-DQB1*02-DQA $1 * 0501$ ) in Caucasians. However, with the advent of new genomic tools and the completion of the human genome and the HapMap projects, new non-HLA genes have been identified and their functional effects on disease aetiology

*The author declares that they have no competing financial interests. started to be dissected as well.

In Caucasians, the first locus shown to be associated with AITDs was the HLA-DRB1 locus (reviewed in [5]). HLA-DR3 (DRB1*03) haplotype has been consistently shown to be associated with GD, with an odds ratio (OR) of 2.0 - 3.0 [6-8]. The literature regarding HT is less consistent with reports of associations with DR3 and DR4 in Caucasians, as well as a negative association with DR 1 and 8, suggesting a protective role [9]. Recently, Zeitlin et al. [10] investigated DRB1-DQB1-DQA1 in the largest UK Caucasian HT case control cohort to date comprising $640 \mathrm{HT}$ patients and 621 controls. A strong association between HT and DR4 haplotype (DRB1*04DQB1*03-DQA $1 * 03$ ) was detected, and protective effects were detected for DR13 haplotype (DRB1*13DQB $1 * 06-\mathrm{DQA} 1 * 01)$ and DR7 [10]. It was recently shown that arginine at position 74 of the DR $\beta 1$ chain (DR/1-Arg74) is important for the development of GD in a significant proportion of patients [11,12]. A study from England provided evidence of a primary association of HLA-C, and to a lesser extent HLA-B, with GD. Other genes have also been shown to influence the expression of GD in Caucasians [13]. These include the genes for cytotoxic T lymphocyte-associated protein 4 (CTLA-4) $[14,15]$, CD40 [16], protein tyrosine phosphatase-22 
(PTPN22) [17], thyroglobulin (Tg) [18,19], and TSH receptor (TSHR) genes [20].

This review will summarize the recent advances in our understanding of the genetic contributions to the etiology of AITD in non-Caucasians (Table 1). Since most of the studies were performed in relatively small size samples recruited from non-Caucasians, the results have some limited.

\section{HLA Genes in Non-Caucasians}

Located on chromosome 6p21 is the major histocompatibility complex region that encodes for HLA glycoproteins. The HLA region is a highly polymorphic region that contains many immune response genes and has been found to be associated with various autoimmune disorders. The HLA molecule binds a peptide antigen (autoantigen in the cause of autoimmunity). It presents the antigen for recognition by the $\mathrm{T}$ cell and as such the $\mathrm{T}$ cell then determines if the antigen is self (and no immune response is mounted) or non-self and an immune response is mounted [21].

The HLA associations are with different alleles in Japanese. In previous studies, HLA-B35 is associated with GD and HLA-DRw53 with HT in the Japanese population (reviewed in [22]). HLA-Bw46 is associated with GD and HLA-DR9 with HT in the Chinese population (reviewed in [22]). The European GD-associated HLA haplotype (HLA-B*08-DRB1*03-DQA1*0501DQB1*02) is virtually absent in Japanese [23]. Dong et al. previously reported that HLA-A*02 and DPB $1 * 0501$ are associated with Japanese GD [24]. Recently, they also demonstrated that HLA-A*02 and DPB $1 * 0202$ showed association with thyroid-stimulating hormonebinding inhibitory immunoglobulins (TBII)-negative GD,

Table 1. A summary of genes investigated for association with AITD in non-Caucasians.

\begin{tabular}{ccc}
\hline Classification & Genes & Authors \\
\hline $\begin{array}{c}\text { Immune } \\
\text { regulatory genes }\end{array}$ & HLA & $\begin{array}{c}\text { Nakabayashi }^{27}, \\
\mathrm{Chu}^{83}\end{array}$ \\
& CTLA-4 & $\begin{array}{c}\text { Furugaki }^{32}, \mathrm{Ban}^{33}, \\
\text { Zhao }^{34}, \mathrm{Chu}^{83}\end{array}$ \\
CD40 & Mukai $^{38}, \mathrm{Ban}^{37}$ \\
PTPN22 & Ichimura $^{44}, \mathrm{Ban}^{45}$ \\
ZFAT & Shirasawa $^{46}$ \\
FCRL3 & Kochi $^{52}, \mathrm{Chu}^{83}$ \\
Thyroid-specific \\
genes
\end{tabular}

AITD, autoimmune thyroid disease. indicating that TBII-negative GD may be genetically distinguished from TBII-positive GD [25]. In addition, Wan et al. reported that HLA-A*02 and DPB4*0101 are associated with Japanese HT [26]. Most recently, Nakabayashi et al. conducted a two-stage genome-wide association study (GWAS) using 1119 Japanese individuals with GD and 2718 unrelated controls, and a subsequent replication study using 432 GD cases and 1157 controls [27]. They identified 34 SNPs to be significantly associated with GD in the GWAS phase, and twenty-two out of 34 SNPs remained positive in the replication study [27]. All 22 SNPs were located within the HLA locus on chromosome $6 \mathrm{p} 21$. Multivariate stepwise logistic regression analysis selected seven out of 22 SNPs, as markers for independent risk loci for GD, although causal variants remain to be identified [27].

\section{Non-HLA Immune-Regulatory Genes in Non-Caucasians}

\subsection{The CTLA-4 Gene}

The cytotoxic T lymphocyte-associated protein 4, CTLA4 , gene is located on chromosome $2 \mathrm{q}$. It is a highly polymorphic gene that was first discovered to be associated with risk for AITD by the candidate gene approach. Under normal circumstances, the CTLA-4 protein acts to suppress $\mathrm{T}$ cell activation during normal immune response in order to prevent $\mathrm{T}$ cell over-activity [28]. CD4 + CD25-T cells only express CTLA- 4 on their surface after the T cell receptor is activated, and its engagement with its ligand suppresses the ongoing immune response. Decreased or absent CTLA-4 activity permits uninhibited T cell activity and a prolonged, unregulated immune response [29], making CTLA-4 an attractive candidate gene for autoimmunity. Indeed, the CTLA-4 gene has been found to be associated with many other autoimmune diseases.

A microsatellite in 3'UTR of CTLA-4 has been linked to AITD in Caucasians (reviewed in [28]); the longer the AT repeats at this site, the less inhibitory activity CTLA-4 has. It has also been associated with AITD in Japanese [30]. Other variants of CTLA-4 gene have been linked to AITD in Caucasians (reviewed in [28]); a G allele substitution at an $\mathrm{A} / \mathrm{G}$ single nucleotide polymerphism (SNP) at position 49 was also found to be associated with AITD in Japanese [31]. Recently, an A/G SNP downstream from the 3'UTR, designated CT60, was found to be associated with GD in Caucasians and has been suggested as the causative variant, albeit this has not been conclusively demonstrated [15]. It was also found to be associated with AITD in Japanese [32,33]. Interestingly, Other SNP (rs231779) is more likely the susceptibility variant for GD in Chinese Han population, suggesting the susceptibility variants of the CTLA- 4 
gene varied between the different geographic populations with GD [34]. Additionally, most recent stratification analyses suggested a possible synergistic interaction of CTLA-4 CT60 with HLA-A*02 and -DPB1*0501 in the susceptibility to TBII-positive GD [35].

\subsection{The CD40 Gene}

The CD40 molecule, located on chromosome 20q, is crucial to both the innate adaptive immune responses. It is present on the surface of antigen presenting cells (APCs) including $\mathrm{B}$ cells. The $\mathrm{T}$ cell-APC interaction results in activation of CD40 as a co-stimulatory molecule. CD40 also plays a critical role in activating B lymphocytes allowing them to terminally differentiate and secrete antibodies (reviewed in [36]). It is no surprise that the CD40 gene has been linked to many autoimmune disorders. Whole genome linkage scanning has identified strong linkage of CD40 to GD. The causative variant predisposing to GD is a $\mathrm{C} / \mathrm{T}$ polymorphism in the Kozak sequence (dbSNP accession number rs1883832), a nucleotide sequence that is essential for the initiation of translation of the CD40 molecule. Specifically, the CC genotype has been identified in Caucasians to be associated with GD [16]. Indeed, functional studies demonstrated that the C-allele of this SNP increased CD40 mRNA translation by $\sim 20 \%-30 \%$ when compared with the protective T allele [28]. We and others have also confirmed an association between the rs 1883832 and GD in Japanese [37,38].

\subsection{The PTPN22 Gene}

The protein tyrosine phosphatase-22 (PTPN22) gene encodes for the lymphoid tyrosine phosphatase (LYP), a molecule that, similar to CTLA-4, functions to inhibit T cell activation [39]. A non-synonymous SNP in the PTPN22 gene, R620W (dbSNP accession number rs2476601), was found to be associated with GD, as well as other autoimmune diseases. This substitution results in a functional change in the LYP protein resulting in activation of $\mathrm{T}$ cell, but the mechanism is unclear [36]. Indeed, this association seems specific for Caucasians and was not found in the Japanese GD population [40].

Recently, the rs2488457 SNP in the promoter region was reported to be associated with acute onset T1D in a Japanese population [41]. However, there was no association of the rs2488457 SNP with GD [42]. Furthermore, the rs3789604 SNP of the PTPN22 gene was found to be associated with RA, independently of rs2476601 [43]. The rs3789604 SNP lies 1496 bases downstream of PTPN22 at the 50 end of the round spermatid basic protein 1 gene (RSBN1), where it encodes either a silent mutation or putative transcription factor-binding sites (TRBS), depending on the transcript. Recently, the AAgenotype and A-allele frequencies of the rs3789604 were significantly higher in GD patients than in control subjects [44], suggesting that the rs3789604 or a gene with linkage disequilibrium may be relevant to susceptibility to GD in Japanese populations. Therefore, we further analyzed five other SNPs including rs12760457, rs2797415, rs1310182, rs2476599, and rs3789604, to clarify whether a susceptibility locus for AITD exists at another location within the PTPN22 gene. Our results showed no association with disease of any of the individual SNPs [45].

Because of the strong LD between five variants, haplotype analysis was undertaken using the computer program SNPAlyze version 7.0. Five haplotypes were identified, three of which (haplotypes 1, 2, and 4) were correlated with haplotypes 1,4 , and 5 identified in the report by Carlton et al. (Table 2) [43]. Four haplotyes (haplotypes 1-4) were relatively common and 1 haplotype was rare. Distribution of the haplotype is significantly different between AITD and control by permutation procedure

Table 2. PTPN22 haplotype structure and frequencies ${ }^{\mathrm{a}}$.

\begin{tabular}{|c|c|c|c|c|c|c|c|c|c|c|c|c|}
\hline \multirow[b]{2}{*}{ Haplotype } & \multicolumn{5}{|c|}{ SNP ID } & \multicolumn{7}{|c|}{ Haplotype comparison ${ }^{\mathrm{b}}$} \\
\hline & 1 & 2 & 3 & 4 & 5 & AITD & GD & HT & Controls & $\begin{array}{l}\text { AITD vs } \\
\text { controls } \\
P \text {-value }\end{array}$ & $\begin{array}{l}\text { GD vs } \\
\text { controls } \\
P \text {-value }\end{array}$ & $\begin{array}{l}\text { HT vs } \\
\text { controls } \\
P \text {-value }\end{array}$ \\
\hline 1 & $\mathrm{C}$ & $\mathrm{T}$ & $\mathrm{T}$ & G & A & 0.59 & 0.59 & 0.59 & 0.60 & 0.69 & 0.75 & 0.69 \\
\hline 2 & $\mathrm{C}$ & $\mathrm{C}$ & $\mathrm{T}$ & G & $\mathrm{C}$ & 0.20 & 0.20 & 0.20 & 0.17 & 0.24 & 0.29 & 0.28 \\
\hline 3 & $\mathrm{C}$ & $\mathrm{C}$ & $\mathrm{C}$ & A & A & 0.13 & 0.13 & 0.13 & 0.12 & 0.54 & 0.66 & 0.47 \\
\hline 4 & $\mathrm{~T}$ & $\mathrm{C}$ & $\mathrm{C}$ & G & A & 0.067 & 0.066 & 0.070 & 0.060 & 0.63 & 0.72 & 0.61 \\
\hline 5 & $\mathrm{C}$ & $\mathrm{C}$ & $\mathrm{T}$ & G & A & 0.013 & 0.017 & 0.0061 & 0.051 & $<0.0001$ & $<0.0001$ & 0.0004 \\
\hline
\end{tabular}

${ }^{\mathrm{a}}$ The program, SNPAlyze ver. 7.0 Standard, was used to estimate common (frequencies $>0.01$ ) haplotypes for the five SNPs genotyped. ${ }^{\mathrm{b}}$ Each haplotype was compared with the other haplotypes combined. SNP: single nucleotide polymorphism; AITD: autoimmune thyroid disease; GD: Graves' disease; HT: Hashimoto's thyroiditis. 
( $p=0.0036)$ [45]. A novel protective effect of a haplotype containing five SNPs was observed $(P<0.0001$ for AITD, $P<0.0001$ for GD, and $P<0.0001$ for HT, respectively) (Table 2) [45].

\subsection{The Zinc-Finger Gene in the AITD Susceptibility Region (ZFAT) Gene}

Shirasawa et al. [46] identified a novel zinc-finger gene, designated ZFAT, as one of the AITD susceptibility genes in 8q23-q24 through an initial association analysis using the probands in their previous linkage analysis [47]. The distance between thyroglobulin and ZFAT genes is about $1.8 \mathrm{M} \mathrm{bp}$. A subsequent association analysis of the samples from a total of 515 affected individuals and 526 controls in Japanese [46]. The T allele of the SNP located in the intron 9 of ZFAT (Ex9b-SNP10) is associated with increased risk for AITDs (dominant model: $\mathrm{OR}=1.7, P=$ $9.1 \times 10^{-5}$ ) [46]. The Ex9b-SNP10 is located in the 3'-UTR of truncated -ZFAT (TR-ZFAT) and the promoter region of the SAS-ZFAT [46]. The human ZFAT gene encodes a 1,243-amino acid residue protein containing one AT-hook and $18 \mathrm{C} 2 \mathrm{H} 2$ zinc-finger domains. ZFAT is also highly conserved among species from fish to human [46]. The ZFAT protein is expressed in the B and $\mathrm{T}$ lymphocytes in mice, and ZFAT regulates the genes involved in immune responses [48]. Furthermore, ZFAT is an anti-apoptotic molecule that is critical for cell survival in human leukemic MOLT-4 cells [49].

\subsection{The FCRL Genes}

Fc receptor-like 3 (FCRL3) is one of five FCRL genes that are preferentially expressed on B-lymphocytes and have a highly structural homology with Fc receptors [50]. The 1p21-23 cytoband, in which the FCRL family resides, has been identified as a candidate locus for multiple autoimmune disorders in both human and murine models [51]. Kochi et al. [52] identified a strong association of SNPs in this region with GD-susceptibility in Japanese and concluded that the origin of the association was a regulatory SNP in the promoter region of FCRL3. This susceptibility gene of GD was first identified from Japanese population. This SNP $(-169 \mathrm{C} / \mathrm{T})(\mathrm{dbSNP}$ accession number rs7522061) alters the binding affinity of NFB and regulates gene expression, and high FCRL3 expression on B-lymphocytes is observed in individuals with the disease-susceptible genotype. The SNP rs7522061 in the FCRL3 gene was also reported to be associated with AITD in Caucasians [53] and two other autoimmune diseases, rheumatoid arthritis (RA) and systemic lupus erythematosus (SLE) [52]. More recently, SNP rs3761959, which tags rs7522061 and rs7528684 (previously associated with RA and GD), was associated with GD in the extended cohort, confirming the original result. In total, three of the seven FCRL3 SNPs showed some evidence for association $(P<0.05)$, with SNP rs11264798 showing the strongest association of the tag SNPs $\left(P=4.0 \times 10^{-3}\right)$ [54]. SNP rs6667109 in FCRL5, which tagged SNPs rs6427384, rs2012199 and rs6679793, all found to be weakly associated in the original study, showed little evidence of association in the extended cohort [54].

\subsection{The FOXP3 Gene}

Two whole genome scans for linkage in GD have shown evidence for linkage at putative X-chromosome loci, $\mathrm{Xq} 21$ [55] and Xp11 [56], and these loci have also been identified in localized linkage scans of the X-chromosome, Xq21 [55] and Xp11 [57], although one of the two genome wide screen increased their numbers and performed an enlarged genome wide screen and no evidence for Xp21 as a region of linkage to GD [58]. In terms of broader relevancy to autoimmunity in general, Xp11 has also been linked to other autoimmune disorders, T1D, multiple sclerosis, and RA, thus suggesting the presence of common susceptibility polymorphism(s) [59-61]. The FOXP3 gene is located at Xp11.23 within this area of autoimmune disease linkage, and is therefore an excellent positional candidate gene for autoimmunity at this locus. Indeed, Bassuny et al. [62] reported an association between a functional microsatellite polymorphism, (GT)n, located in the promoter/enhancer region of FOXP3, and T1D in a Japanese population. However, a subsequent study could not confirm the FOXP3 association with T1D in an Italian population [63]. A recent study from the UK tested several FOXP3 polymorphisms for associations with GD, and found no robust evidence that those polymorphisms contributes to the susceptibility to GD [64]. We tested the FOXP3 gene locus for associations with AITDs in two cohorts of US Caucasians and Japanese AITD patients [65]. Our study demonstrated a weak association between polymorphisms of the FOXP3 gene and AITD in US Caucasians but not in the Japanese. However, One group from Japanese reported that the $-3279 \mathrm{~A} / \mathrm{C}$ SNP of the FOXP3 gene is related to the development and intractability of GD and the $-2383 \mathrm{CC}$ genotype to the severity of HT [66]. These results, if replicated, may suggest that inherited abnormalities of Treg function may contribute to the etiology of AITD.

\section{Thyroid-Specific Genes in Non-Caucasians}

\subsection{The Thyroglobulin Gene}

The thyroglobulin $(\mathrm{Tg})$ protein is the major thyroidal protein antigen and is a precursor to thyroid hormones. 
Tg is also a key antigen in AITD as evidenced by the fact HT is characterized by anti-thyroglobulin antibodies which are detected in $75 \%$ of patients [36]. Whole genome linkage studies identified a locus on chromosome $8 \mathrm{q} 24$ that was linked with AITD; this locus contained the Tg gene [67]. Sequencing of the Tg gene identified several non-synonymous SNPs that were associated with AITD [68]. In our dataset of Japanese AITD patients we found an association between a $\mathrm{Tg}$ microsatellite polymorphism and HT [69]. Most recently, we performed a case-control study of AITD using 25 SNPs from the Single Nucleotide Polymorphism Database (dbSNP) databases spaced approximately $10-50 \mathrm{~kb}$ apart and spanning the $\mathrm{Tg}$ gene, and found significant associations between two strongest associated SNPs in intron 41 and GD (Table 3) [70]. Our results suggest that Tg is a susceptibility gene for AITD in the Japanese population. Therefore, it is possible that that the $\mathrm{Tg}$ gene may predispose to AITD across populations of different ethnic backgrounds.

\subsection{TSH Receptor (TSHR) Gene}

The TSHR gene is located on chromosome 14q. It was found to be associated with GD both by the candidate gene approach and by whole genome linkage studies [67]. The TSHR gene was a prime candidate gene for GD since GD is caused by autoantibodies that bind to and stimulate the TSH receptor. Several TSHR SNPs have been tested for association with GD, including non-synonymous SNPs in the extracellular TSH receptor domain and in the intracellular domain of the TSHR; all of these gave conflicting results [71]. However, linkage studies demonstrated significant evidence for linkage of GD with a locus on chromosome $14 \mathrm{q}$ harbouring the TSHR gene and many other genes [67]. It was later found that noncoding SNPs in intron 1 of the TSHR confer the association with GD [72]. Recently, association within the TSHR intron 1 in Caucasians was narrowed down to two SNPs (rs179247 and rs12101255) within intron 1 [73]. The disease-associated genotypes of rs179247 (AA) and rs12101255 (TT) showed reduced mRNA expression ratios of flTSHR relative to two alternate TSHR mRNA splice viriants [73]. Ploski et al. [74] validated association of TSHR intron 1 SNPs with GD in three independent European cohorts and demonstrated that the etiological variant within the TSHR is likely to be in strong linkage disequilibrium with rs12101255. In Japanese, mltiple SNPs in intron 7 of TSHR gene were associated with GD [75].

\section{Conclusions}

Through the genetic studies undertaken to date, we now know that substantial ethnic differences exist in AITD genetic predisposition between populations of Caucasian and Japanese ancestries. Beside the HLA-DRB1 alleles as described, the most evident ethnic difference is seen in the non-synonymous coding polymorphism of the PTPN22 gene in Caucasian populations. This polymorphism is rarely found in Japanese population [40], and thus specifically contributes to AITD in populations of Caucasian descent. The absence of a disease-risk allele in a population, as in the case of PTPN22, can easily explain the genetic heterogeneity between populations [76]. However, the situation is more complex in cases where the disease-risk allele is shared among different populations, and the results of association tests are not. This

Table 3. Case-control association results for the two most highly GD associated SNPs.

\begin{tabular}{|c|c|c|c|c|c|c|c|c|}
\hline SNP name & $\begin{array}{c}\text { Allele/ } \\
\text { genotype }\end{array}$ & Control $(n=221)$ & $\operatorname{AITD}(n=458)$ & $P$-value ${ }^{a}$ & GD (n = 287) & $P$-value ${ }^{a}$ & HT $(n=171)$ & $P$-value ${ }^{\mathrm{a}}$ \\
\hline \multirow[t]{5}{*}{ rs 2256366} & $\mathrm{~T}$ & $248(56.1)$ & $452(49.3)$ & & $266(46.3)$ & & $452(54.4)$ & \\
\hline & $\mathrm{C}$ & $194(43.9)$ & $464(50.7)$ & 0.019 & $308(53.7)$ & 0.002 & $464(45.6)$ & 0.63 \\
\hline & $\mathrm{T} / \mathrm{T}$ & $72(32.6)$ & $108(23.6)$ & & $59(20.6)$ & & $108(28.7)$ & \\
\hline & $\mathrm{T} / \mathrm{C}$ & $104(47.1)$ & $236(51.5)$ & & $148(51.6)$ & & $236(51.5)$ & \\
\hline & $\mathrm{C} / \mathrm{C}$ & $45(20.4)$ & $114(24.9)$ & 0.04 & $80(27.9)$ & 0.0056 & $114(19.9)$ & 0.65 \\
\hline \multirow[t]{5}{*}{ rs 2687836} & $\mathrm{C}$ & $265(60.0)$ & $499(54.5)$ & & $296(51.6)$ & & $203(59.4)$ & \\
\hline & $\mathrm{T}$ & $177(40.0)$ & $417(45.5)$ & 0.057 & $278(48.4)$ & 0.0077 & $139(40.6)$ & 0.87 \\
\hline & $\mathrm{C} / \mathrm{C}$ & $81(36.7)$ & $131(28.6)$ & & $73(25.4)$ & & $58(33.9)$ & \\
\hline & $\mathrm{C} / \mathrm{T}$ & $103(46.6)$ & $237(51.7)$ & & $150(52.2)$ & & 87 (50.9) & \\
\hline & $\mathrm{T} / \mathrm{T}$ & $37(16.7)$ & $90(19.7)$ & 0.10 & $64(22.3)$ & 0.019 & $26(15.2)$ & 0.70 \\
\hline
\end{tabular}

Values given are the number of subjects, with the percentage in parentheses. ${ }^{\text {a }}$-value based on $x^{2}$ distribution. SNP: single nucleotide polymorphism. AITD: autoimmune thyroid disease. GD: Graves' disease. HT: Hashimoto's thyroiditis. 
could occur when: 1) a positive association in the primary report represents a false-positive due to sampling biases; 2) a negative association observed in a replication study is a false-negative due to a lack of statistical power; or 3) true genetic heterogeneity exists (genetic contribution of the gene polymorphisms is zero in a population, or lower than that of the population originally reported) [76].

The most recent step in the evolution of genetic studies in common disease sees association analysis performed at a genome-wide level to produce genome-wide association studies [77-79]. These studies, now beginning to emerge in some common diseases bring together the latest advances in our genetic maps, large scale automated genotyping technologies and large national DNA collections [80-82]. Genotyping technology is now being utilized which is able to produce information on over 500,000 SNPs in cohorts of between 2000 and 3000 samples. These studies will not only help identify novel loci but should also provide insights into the different technical, analytical, methodological and biological aspects of genome-wide association analysis. Assuming that these new approaches deliver some novel loci an important next step will be the validation and replication of loci that will then justify more detailed fine mapping and functional analyses. Recently, one group from China conducted a genome-wide association study in 1536 individuals with GD (cases) and 1516 controls, and further evaluated a group of associated SNPs in a second set of 3994 cases and 3510 controls [83]. They confirmed four previously reported loci (in the HLA, TSHR, CTLA4 and FCRL3) and identified two new susceptibility loci (the RNASET2-FGFR1OP-CCR6 region at 6q27 and an intergenic region at 4p14) [83]. Most recently, Cooper et al. [84] conducted an association study using a custom-made SNP array, the ImmunoChip to further investigate the genetic determinants of AITD. The SNP array contains all known and genotype-able SNPs across 186 distinct susceptibility loci associated with one or more immune-mediated diseases [84]. After stringent quality control, they analyzed 103875 common SNPs (minor allele frequency $>0.05$ ) in 2285 GD and 462 HT patients and 9364 controls [84]. They found evidence for seven new AITD risk loci $\left(P<1.12 \times 10^{-6}\right.$; a permutation test derived significance threshold), five at locations previously associated and two at locations awaiting confirmation, with other immune-mediated diseases [84]. Since genetic heterogeneity of disease susceptibility variants between ethnic groups is common in complex diseases, following up this work will be important in the future.

Genetic analyses undertaken in the last decade have revealed a completely new picture of AITD pathogenesis and made us aware of heterogeneity among individuals and populations. Our final goal is to establish new treat- ments for AITD, based on the pathogenesis and prognosis of individuals, which could lead to the development of tailor-made therapies for AITD. To reach this goal, we should continue to uncover unknown genetic predispositions and clarify differences in roles among ethnicities. Upcoming genome-wide scans for additional populations worldwide and the meta-analysis of these studies may elucidate the complete picture of AITD.

\section{Acknowledgements}

This work was supported in part by a Showa University Grant-in-aid for Innovative Collaborative Research Projects (to Yoshiyuki Ban), a grant from the Showa University School of Medicine Alumni Association (to Yoshiyuki Ban), and a grant from the Yamaguchi Endocrine Research Association (to Yoshiyuki Ban).

\section{REFERENCES}

[1] A. Huber, F. Menconi, S. Corathers, E. M. Jacobson and Y. Tomer, "Joint Genetic Susceptibility to Type 1 Diabetes and Autoimmune Thyroiditis: From Epidemiology to Mechanisms," Endocrine Reviews, Vol. 29, No. 6, 2008, pp. 697-725. doi:10.1210/er.2008-0015

[2] D. L. Jacobson, S. J. Gange, N. R. Rose and N. M. Graham, "Epidemiology and Estimated Population Burden of Selected Autoimmune Diseases in the United States," Clinical Immunology and Immunopathology, Vol. 84, No. 3, 1997, pp. 223-243. doi:10.1006/clin.1997.4412

[3] A. P. Weetman, "Chronic Autoimmune Thyroiditis," In: L. E. Braverman and R. D. Utiger, Eds., Werner and Ingbar's Thyroid, Lippincott Williams and Wilkins, Philadelphia, 2000, pp. 721-732.

[4] F. Menconi, Y. L. Oppenheim and Y. Tomer, "Graves' Disease," In: Y. Shoenfeld, R. Cervera and M. E. Gershwin, Eds., Diagnostic Criteria in Autoimmune Diseases, Humana Press, Totowa, 2008, pp. 231-235. doi:10.1007/978-1-60327-285-8 44

[5] Y. Tomer and T. F. Davies, "Searching for the Autoimmune Thyroid Disease Susceptibility Genes: From Gene Mapping to Gene Function," Endocrine Reviews, Vol. 24, No. 5, 2003, pp. 694-717. doi:10.1210/er.2002-0030

[6] V. Stenszky, L. Kozma, C. Balazs, S. Rochlitz, J. C. Bear and N. R. Farid, “The Genetics of Graves' Disease: HLA and Disease Susceptibility," The Journal of Clinical Endocrinology \& Metabolism, Vol. 61, No. 4, 1985, pp. 735-740. doi:10.1210/jcem-61-4-735

[7] A. Mangklabruks, N. Cox and L. J. DeGroot, "Genetic Factors in Autoimmune Thyroid Disease Analyzed by Restriction Fragment Length Polymorphisms of Candidate Genes," The Journal of Clinical Endocrinology \& Metabolism, Vol. 73, No. 2, 1991, pp. 236-244. doi:10.1210/jcem-73-2-236

[8] J. M. Heward, A. Allahabadia, J. Daykin, et al., "Linkage Disequilibrium between the Human Leukocyte Antigen Class II Region of the Major Histocompatibility Complex and Graves' Disease: Replication Using a Population 
Case Control and Family-Based Study," The Journal of Clinical Endocrinology \& Metabolism, Vol. 83, No. 10, 1998, pp. 3394-3397. doi:10.1210/jc.83.10.3394

[9] F. Menconi, M. C. Monti, D. A. Greenberg, et al., "Molecular Amino Acid Signatures in the MHC Class II Peptide-Binding Pocket Predispose to Autoimmune Thyroiditis in Humans and in Mice," Procedings of National Academy Sciences of USA, 2008, pp. 14034-14039. doi:10.1073/pnas.0806584105

[10] A. A. Zeitlin, J. M. Heward, P. R. Newby, et al., "Analysis of HLA Class II Genes in Hashimoto's Thyroiditis Reveals Differences Compared to Graves' Disease," Genes and Immunity, Vol. 9, No. 4, 2008, pp. 358-363. doi:10.1038/gene.2008.26

[11] Y. Ban, T. F. Davies, D. A. Greenberg, et al., "Arginine at Position 74 of the HLA-DRb1 Chain Is Associated with Graves' Disease," Genes and Immunity, Vol. 5, No. 3, 2004, pp. 203-208. doi:10.1038/sj.gene.6364059

[12] M. J. Simmonds, J. M. Howson, J. M. Heward, et al., "Regression Mapping of Association between the Human Leukocyte Antigen Region and Graves Disease," American Journal of Human Immunology, Vol. 76, No. 1, 2005, pp. 157-163. doi:10.1086/426947

[13] M. J. Simmonds, J. M. Howson, J. M. Heward, et al., “A Novel and Major Association of HLA-C in Graves' Disease that Eclipses the Classical HLA-DRB1 Effect," Human Molecular Genetics, Vol. 16, No. 18, 2007, pp. 21492153. doi: $10.1093 / \mathrm{hmg} / \mathrm{ddm} 165$

[14] T. Yanagawa, Y. Hidaka, V. Guimaraes, M. Soliman and L. J. DeGroot, "CTLA-4 Gene Polymorphism Associated with Graves' Disease in a Caucasian Population," The Journal of Clinical Endocrinology \& Metabolism, Vol. 80, No. 1, 1995, pp. 41-45. doi:10.1210/jc.80.1.41

[15] H. Ueda, J. M. Howson, L. Esposito, et al., "Association of the T-Cell Regulatory Gene CTLA4 with Susceptibility to Autoimmune Disease," Nature, Vol. 423, No. 6939, 2003, pp. 506-511. doi:10.1038/nature01621

[16] Y. Tomer, E. Concepcion and D. A. Greenberg, “A C/T Single Nucleotide Polymorphism in the Region of the CD40 Gene Is Associated with Graves' Disease," Thyroid, Vol. 12, No. 12, 2002, pp. 1129-1135. doi: $10.1089 / 105072502321085234$

[17] D. Smyth, J. D. Cooper, J. E. Collins, et al., "Replication of an Association between the Lymphoid Tyrosine Phosphatase Locus (LYP/PTPN22) with Type 1 Diabetes, and Evidence for Its Role as a General Autoimmunity Locus," Diabetes, Vol. 53, No. 11, 2004, pp. 3020-3023. doi:10.2337/diabetes.53.11.3020

[18] Y. Tomer, D. A. Greenberg, E. Concepcion, Y. Ban and T. F. Davies, "Thyroglobulin Is a Thyroid Specific Gene for the Familial Autoimmune Thyroid Diseases," The Journal of Clinical Endocrinology \& Metabolism, Vol. 87, No. 1, 2002, pp. 404-407. doi:10.1210/jc.87.1.404

[19] J. E. Collins, J. M. Heward, J. Carr-Smith, J. Daykin, J. A. Franklyn and S. C. Gough, "Association of a Rare Thyroglobulin Gene Microsatellite Variant with Autoimmune Thyroid Disease," The Journal of Clinical Endocrinology \& Metabolism, Vol. 88, No. 10, 2003, pp. 5039-5042. doi:10.1210/jc.2003-030093
[20] B. M. Dechairo, D. Zabaneh, J. Collins, et al., "Association of the TSHR Gene with Graves' Disease: The First Disease Specific Locus," European Journal of Human Genetics, Vol. 13, No. 11, 2005, pp. 1223-1230. doi:10.1038/sj.ejhg.5201485

[21] J. A. Gebe, E. Swanson and W. W. Kwok, "HLA Class II Peptide-Binding and Autoimmunity," Tissue Antigens, Vol. 59, No. 2, 2002, pp. 78-87. doi:10.1034/j.1399-0039.2002.590202.x

[22] E. M. Jacobson, A. Huber and Y. Tomer, "The HLA Gene Complex in Thyroid Autoimmunity: From Epidemiology to Etiology," Journal of Autoimmunity, Vol. 30, No. 1-2, 2008, pp. 58-62.

[23] S. Saito, S. Ota, E. Yamada, H. Inoko and M. Ota, "Allele Frequencies and Haplotypic Associations Defined by Allelic DNA Typing at HLA Class I and Class II Loci in the Japanese Population," Tissue Antigens, Vol. 56, No. 6, 2000, pp. 522-529. doi:10.1034/j.1399-0039.2000.560606.x

[24] R. P. Dong, A. Kimura, R. Okubo, et al., "HLA-A and DPB1 Loci Confer Susceptibility to Graves' Disease," Human Immunology, Vol. 35, No. 1-2, 1992, pp. 165-172. doi:10.1016/0198-8859(92)90101-R

[25] M. Takahashi, M. Yasunami, S. Kubota, H. Tamai and A. Kimura, "HLA-DPB1*0202 Is Associated with a Predictor of Good Prognosis of Graves' Disease in Japanese," Human Immunology, Vol. 67, No. 1-2, 2006, pp. 47-52. doi:10.1016/j.humimm.2006.02.023

[26] X. L. Wan, A. Kimura, R. P. Dong, K. Honda, H. Tamai and T. Sasazuki, "HLA-A and -DRB4 Genes in Controlling the Susceptibility to Hashimoto's Thyroiditis," $\mathrm{Hu}$ man Immunology, Vol. 42, No. 2, 1995, pp. 131-136. doi:10.1016/0198-8859(94)00089-9

[27] K. Nakabayashi, A. Tajima, K. Yamamoto, et al., "Identification of Independent Risk Loci for Graves' Disease within the MHC in the Japanese Population," Journal of Human Genetics, Vol. 56, No. 11, 2011, pp. 772-778. doi:10.1038/jhg.2011.99

[28] Y. Tomer, "Genetic Susceptibility to Autoimmune Thyroid Disease: Past, Present, and Future," Thyroid, Vol. 20, No. 7, 2010, pp. 715-725. doi:10.1089/thy.2010.1644

[29] R. Khattri, J. A. Auger, M. D. Griffin, A. H. Sharpe and J. A. Bluestone, "Lymphoproliferative Disorder in CTLA-4 Knockout Mice Is Characterized by CD 28-Regulated Activation of Th2 Responses," Journal of Immunology, Vol. 162, No. 10, 1999, pp. 5784-5791.

[30] M. M. Sale, T. Akamizu, T. D. Howard, et al., "Association of Autoimmune Thyroid Disease with a Microsatellite Marker for the Thyrotropin Receptor Gene and CTLA-4 in a Japanese Population," Proceedings of the Association of American Physicians, Vol. 109, No. 5, 1997, pp. 453-461.

[31] T. Yanagawa, M. Taniyama, S. Enomoto, et al., "CTLA-4 Gene Polymorphism Confers Susceptibility to Graves' Disease in Japanese," Thyroid, Vol. 7, No. 6, 1997, pp. 843-846. doi:10.1089/thy.1997.7.843

[32] K. Furugaki, S. Shirasawa, N. Ishikawa, et al., "Association of the T-Cell Regulatory Gene CTLA-4 with Graves' 
Disease and Autoimmune Thyroid Disease in Japanese," Journal of Human Genetics, Vol. 49, No. 3, 2004, pp. 166-168. doi:10.1007/s10038-003-0120-5

[33] Y. Ban, T. Tozaki, M. Taniyama, M. Tomita and Y. Ban, “Association of a CTLA-43' Untranslated Region (CT60) Single Nucleotide Polymorphism with Autoimmune Thyroid Disease in the Japanese Population," Autoimmunity, Vol. 38, No. 2, 2005, pp. 151-153. doi:10.1080/08916930500050319

[34] S. X. Zhao, C. M. Pan, H. M. Cao, et al., "Association of the CTLA-4 Gene with Graves' Disease in the Chinese Han Population," PLOS ONE, Vol. 5, No. 3, 2010, p. e9821. doi:10.1371/journal.pone.0009821

[35] M. Takahashi and A. Kimura, "HLA and CTLA-4 Polymorphisms May Confer a Synergistic Risk in the Susceptibility to Graves' Disease," Journal of Human Genetics, Vol. 55, No. 5, 2010, pp. 323-326. doi:10.1038/jhg.2010.20

[36] E. M. Jacobson and Y. Tomer, "The CD40, CTLA-4, Thyroglobulin, TSH Receptor, and PTPN22 Gene Quintet and Its Contribution to Thyroid Autoimmunity: Back to the Future," Journal of Autoimmunity, Vol. 28, No. 2-3, 2007, pp. 85-89. doi:10.1016/j.jaut.2007.02.006

[37] Y. Ban, T. Tozaki, M. Taniyama, M. Tomita and Y. Ban, "Association of a C/T Single-Nucleotide Polymorphism in the 5' Untranslated Region of the CD40 Gene with Graves' Disease in Japanese," Thyroid, Vol. 16, No. 5, 2006, pp. 443-446. doi:10.1089/thy.2006.16.443

[38] T. Mukai, Y. Hiromatsu, T. Fukutani, et al., "A C/T Polymorphism in the 5'Untranslated Region of the CD40 Gene Is Associated with Later Onset of Graves' Disease in Japanese," Endocrine Journal, Vol. 52, No. 4, 2005, pp. 471-477. doi:10.1507/endocri.52.471

[39] S. A. Chung and L. A. Criswell, "PTPN22: Its Role in SLE and Autoimmunity," Autoimmunity, Vol. 40, No. 8, 2007, pp. 582-590. doi:10.1080/08916930701510848

[40] Y. Ban, T. Tozaki, M. Taniyama, M. Tomita and Y. Ban, "The Codon 620 Single Nucleotide Polymorphism of the Protein Tyrosine Phosphatase-22 Gene Does Not Contribute to Autoimmune Thyroid Disease Susceptibility in Japanese," Thyroid, Vol. 15, No. 10, 2005, pp. 1115-1118. doi:10.1089/thy.2005.15.1115

[41] E. Kawasaki, T. Awata, H. Ikegami, et al., "Systematic Search for Single Nucleotide Polymorphisms in a Lymphoid Tyrosine Phosphatase Gene (PTPN22): Association between a Promoter Polymorphism and Type 1 Diabetes in Asian Populations," American Journal of Medical Genetics A, Vol. 140, No. 6, 2006, pp. 586-593. doi:10.1002/ajmg.a.31124

[42] M. Ichimura, H. Kaku, T. Fukutani, et al., "Associations of Protein Tyrosine Phosphatase Nonreceptor 22 (PTPN22) Gene Polymorphisms with Susceptibility to Graves' Disease in a Japanese Population," Thyroid, Vol. 18, No. 6, 2008, pp. 625-630. doi:10.1089/thy.2007.0353

[43] V. E. Carlton, X. Hu, A. P. Chokkalingam, et al., "PTPN22 Genetic Variation: Evidence for Multiple Variants Associated with Rheumatoid Arthritis," The American Journal of Human Genetics, Vol. 77, No. 4, 2005, pp. 567-581. doi:10.1086/468189
[44] M. Ichimura, H. Kaku, T. Fukutani, et al., "Associations of Protein Tyrosine Phosphatase Nonreceptor 22 (PTPN22) Gene Polymorphisms with Susceptibility to Graves' Disease in a Japanese Population," Thyroid, Vol. 18, No. 6, 2008, pp. 625-630. doi:10.1089/thy.2007.0353

[45] Y. Ban, T. Tozaki, M. Taniyama, et al., "Association of the Protein Tyrosine Phosphatase-22 (PTPN22) Haplotypes with Autoimmune Thyroid Disease in the Japanese Population," Thyroid, Vol. 20, No. 8, 2010, pp. 893-899. doi:10.1089/thy.2010.0104

[46] S. Shirasawa, H. Harada, K. Furugaki, et al., "SNPs in the Promoter of a B Cell-Specific Antisense Transcript, SAS-ZFAT, Determine Susceptibility to Autoimmune Thyroid Disease," Human Molecular Genetics, Vol. 13, No. 19, 2004, pp. 2221-2231. doi:10.1093/hmg/ddh245

[47] K. Sakai, S. Shirasawa, N. Ishikawa, et al., "Identification of Susceptibility Loci for Autoimmune Thyroid Disease to 5q31-q33 and Hashimoto's Thyroiditis to 8q23-q24 by Multipoint Affected Sib-Pair Linkage Analysis in Japanese," Human Molecular Genetics, Vol. 10, No. 13, 2001, pp. 1379-1386. doi:10.1093/hmg/10.13.1379

[48] M. Koyanagi, K. Nakabayashi, T. Fujimoto, et al., "ZFAT Expression in B and T Lymphocytes and Identification of ZFAT-Regulated Genes," Genomics, Vol. 91, No. 5, 2008, pp. 451-457. doi:10.1016/j.ygeno.2008.01.009

[49] T. Fujimoto, K. Doi, M. Koyanagi, et al., "ZFAT Is an Antiapoptotic Molecule and Critical for Cell Survival in MOLT-4 Cells," Federation of European Biochemical Societies, Vol. 583, No. 3, 2009, pp. 568-572. doi:10.1016/j.febslet.2008.12.063

[50] R. S. Davis, "Fc Receptor-Like Molecules," Annual Review of Immunology, Vol. 25, No. 1, 2007, pp. 525-560. doi:10.1146/annurev.immunol.25.022106.141541

[51] P. Marrack, J. Kappler and B. L. Kotzin, "Autoimmune Disease: Why and Where It Occurs," Nature Medicine, Vol. 7, No. 8, 2001, pp. 899-905. doi:10.1038/90935

[52] Y. Kochi, R. Yamada, A. Suzuki, et al., "A Functional Variant in FCRL3, Encoding Fc Receptor-Like 3, Is Associated with Rheumatoid Arthritis and Several Autoimmunities," Nature Genetics, Vol. 37, No. 5, 2005, pp. 478485. doi: $10.1038 / \mathrm{ng} 1540$

[53] M. J. Simmonds, J. M. Heward, J. Carr-Smith, H. Foxall, J. A. Franklyn and S. C. Gough, "Contribution of Single Nucleotide Polymorphisms within FCRL3 and MAP3K7IP2 to the Pathogenesis of Graves' Disease," The Journal of Clinical Endocrinology \& Metabolism, Vol. 91, No. 3, 2006, pp. 1056-1061. doi: $10.1210 /$ jc. $2005-1634$

[54] Wellcome Trust Case Control Consortium, "The Australo-Anglo-American Spodylitis Consortium. Association Scan of 14,500 Nonsynonymous SNPs in Four Diseases Identifies Autoimmunity Variants," Nature Genetics, Vol. 39, No. 11, 2007, pp. 1329-1337.

[55] Y. Tomer, G. Barbesino, D. A Greenberg, E. S. Concepcion and T. F. Davies, "Mapping the Major Susceptibility Loci for Familial Graves' and Hashimoto's Diseases: Evidence for Genetic Heterogeneity and Gene Interactions," The Journal of Clinical Endocrinology \& Metabo- 
lism, Vol. 84, No. 12, 1999, pp. 4656-4664. doi: $10.1210 /$ jc. 84.12 .4656

[56] J. C. Taylor, S. C. Gough, P. J. Hunt, T. H. Brix, K. Chatterjee, J. M. Connell, J. A. Franklyn, L. Hegedus, B. G. Robinson, W. M. Wiersinga, J. A. Wass, D. Zabaneh, I. Mackay and A. P. Weetman, "A Genome-Wide Screen in 1119 Relative Pairs with Autoimmune Thyroid Disease," The Journal of Clinical Endocrinology \& Metabolism, Vol. 91, No. 2, 2005, pp. 646-653. doi:10.1210/jc.2005-0686

[57] H. Imrie, B. Vaidya, P. Perros, W. F. Kelly, A. D. Toft, E. T. Young and P. Kendall-Taylor, "Pearce SHS. Evidence for a Graves' Disease Susceptibility Locus at Chromosome Xp11 in a United Kingdom Population," The Journal of Clinical Endocrinology \& Metabolism, Vol. 86, No. 2, 2001, pp. 626-630. doi:10.1210/jc.86.2.626

[58] Y. Tomer, Y. Ban, E. Concepcion, G. Barbesino, R. Villanueva, D. A. Greenberg and T. F. Davies, "Common and Unique Susceptibility Loci in Graves and Hashimoto Diseases: Results of Whole-Genome Screening in a Data Set of 102 Multiplex Families," The American Journal of Human Genetics, Vol. 73, No. 4, 2003, pp. 736-747. doi: $10.1086 / 378588$

[59] G. C. Ebers, K. Kukay, D. E. Bulman, A. D. Sadovnick, G. Rice, C. Anderson, H. Armstrong, K. Cousin, R. B. Bell, W. Hader, D. W. Paty, S. Hashimoto, J. Oger, P. Duquette, S. Warren, T. Gray, P. O'Connor, A. Nath, A. Auty, L. Metz, G. Francis, J. E. Paulseth, T. J. Murray, W. Pryse-Phillips, R. Nelson, M. Freedman, D. Brunet, J. P. Bouchard, D. Hinds and N. Risch, "A Full Genome Search in Multiple Sclerosis," Nature Genetics, Vol. 13, No. 4, 1996, pp. 472-476. doi:10.1038/ng0896-472

[60] F. Cornélis, S. Fauré, M. Martinez, J.-F. Prud'homme, P. Fritz, C. Dib, H. Alves, P. Barrera, N. de Vries, A. Balsa, D. Pascual-Salcedo, K. Maenaut, R. Westhovens, P. Migliorini, T. H. Tran, A. Delaye, N. Prince, C. Lefevre, G. Thomas, M. Poirier, S. Soubigou, O. Alibert, S. Lasbleiz, S. Fouix, C. Bouchier, F. Lioté, M. N. Loste, V. Lepage, D. Charron, G. Gyapay, A. Lopes-Vaz, D. Kuntz, T. Bardin and J. Weissenbach, "ECRAF. New Susceptibility Locus for Rheumatoid Arthritis Suggested by a Genome-Wide Linkage Study," Proceedings of the National Academy of Sciences of the United States of America, Vol. 95, No. 18, 1998, pp. 10746-10750.

[61] F. Cucca, J. V. Goy, Y. Kawaguchi, L. Esposito, M. E. Merriman, A. J. Wilson, H. J. Cordell, S. C. Bain and J. A. Todd, "A Male-Female Bias in Type 1 Diabetes and Linkage to Chromosome Xp in MHC HLA-DR3-Positive Patients," Nature Genetics, Vol. 19, No. 3, 1998, pp. 301302. doi:10.1038/995

[62] W. M. Bassuny, K. Ihara, Y. Sasaki, R. Kuromaru, H. Kohno, N. Matsuura and T. Hara, "A Functional Polymorphism in the Promoter/Enhancer Region of the FOXP3/Scurfin Gene Associated with Type 1 Diabetes," Immunogenetics, Vol. 55, No. 3, 2003, pp. 149-156. doi:10.1007/s00251-003-0559-8

[63] P. Zavattari, E. Deidda, M. Pitzalis, B. Zoa, L. Moi, R. Lampis, D. Contu, C. Motzo, P. Frongia, E. Angius, M. Maioli, J. A. Todd and F. Cucca, "No Association between Variation of the FOXP3 Gene and Common Type
1 Diabetes in the Sardinian Population," Diabetes, Vol. 53, No. 7, 2004, pp. 1911-1914. doi:10.2337/diabetes.53.7.1911

[64] C. J. Owen, J. A. Eden, C. E. Jennings, V. Wilson, T. D. Cheetham and S. H. Pearce, "Genetic Association Studies of the FOXP3 Gene in Graves' Disease and Autoimmune Addison's Disease in the United Kingdom Population," Journal of Molecular Endocrinology, Vol. 37, No. 1, 2006, pp. 97-104. doi:10.1677/jme.1.02072

[65] Y. Ban, T. Tozaki, T. Tobe, Y. Ban, E. M. Jacobson, E. S. Concepcion and Y. Tomer, "The Regulatory T Cell Gene FOXP3 and Genetic Susceptibility to Thyroid Autoimmunity: An Association Analysis in Caucasian and Japanese Cohorts," Journal of Autoimmunity, Vol. 28, No. 4, 2007, pp. 201-207. doi:10.1016/j.jaut.2007.02.016

[66] N. Inoue, M. Watanabe, M. Morita, R. Tomizawa, T. Akamizu, K. Tatsumi, Y. Hidaka and Y. Iwatani, "Association of Functional Polymorphisms Related to the Transcriptional Level of FOXP3 with Prognosis of Autoimmune Thyroid Diseases," Clinical \& Experimental Immunology, Vol. 162, No. 3, 2010, pp. 402-406. doi:10.1111/j.1365-2249.2010.04229.x

[67] Y. Tomer, Y. Ban, E. Concepcion, et al., "Common and Unique Susceptibility Loci in Graves and Hashimoto Diseases: Results of Whole-Genome Screening in a Data Set of 102 Multiplex Families," The American Journal of Human Genetics, Vol. 73, No. 4, 2003, pp. 736-747. doi:10.1086/378588

[68] Y. Ban, D. A. Greenberg, E. Concepcion, L. Skrabanek, R. Villanueva and Y. Tomer, "Amino Acid Substitutions in the Thyroglobulin Gene Are Associated with Susceptibility to Human and Murine Autoimmune Thyroid Disease," Proceedings of the National Academy of Sciences of the United States of America, Vol. 100, No. 25, 2003, pp. 15119-15124. doi:10.1073/pnas.2434175100

[69] Y. Ban, T. Tozaki, M. Taniyama and M. Tomita, "Association of a Thyroglobulin Gene Polymorphism with Hashimoto's Thyroiditis in the Japanese Population," Clinical Endocrinology, Vol. 61, No. 2, 2004, pp. 263268. doi:10.1111/j.1365-2265.2004.02096.x

[70] Y. Ban, T. Tozaki, M. Taniyama, L. Skrabanek, Y. Nakano and T. Hirano, "Multiple SNPs in Intron 41 of Thyroglobulin Gene Are Associated with Autoimmune Thyroid Disease in the Japanese Population," PLOS ONE, Vol. 7, No. 5, 2012, p. e37501. doi:10.1371/journal.pone.0037501

[71] A. A. Zeitlin, M. J. Simmonds and S. C. L. Gough, "Genetic Developments in Autoimmune Thyroid Disease: An Evolutionary Process," Clinical Endocrinology, Vol. 68, No. 5, 2008, pp. 671-682. doi:10.1111/j.1365-2265.2007.03075.x

[72] B. M. Dechairo, D. Zabaneh, J. Collins, et al., "Association of the TSHR Gene with Graves' Disease: The First Disease Specific Locus," European Journal of Human Genetics, Vol. 13, No. 11, 2005, pp. 1223-1230. doi:10.1038/sj.ejhg.5201485

[73] O. J. Brand, J. C. Barrett, M. J. Simmonds, et al., "Association of the Thyroid Stimulating Hormone Receptor Gene (TSHR) with Graves' Disease," Human Molecular 
Genetics, Vol. 18, No. 9, 2009, pp. 1704-1713. doi: $10.1093 / \mathrm{hmg} / \mathrm{ddp} 087$

[74] R. Ploski, O. J. Brand, B. Jurecka-Lubieniecka, et al., "Thyroid Stimulating Hormone Receptor (TSHR) Intron 1 Variants Are Major Risk Factors for Graves' Disease in Three European Caucasian Cohorts," PLOS ONE, Vol. 5, No. 11, 2010, p. e15512. doi:10.1371/journal.pone.0015512

[75] H. Hiratani, D. W. Bowden, S. Ikegami, et al., "Multiple SNPs in Intron 7 of Thyrotropin Receptor Are Associated with Graves' Disease," The Journal of Clinical Endocrinology \& Metabolism, Vol. 90, No. 5, 2005, pp. 28982903. doi:10.1210/jc.2004-2148

[76] Y. Kochi, A. Suzuki, R. Yamada and K. Yamamoto, "Genetics of Rheumatoid Arthritis: Underlying Evidence of Ethnic Differences," Journal of Autoimmunity, Vol. 32, No. 3-4, 2009, pp. 158-162. doi:10.1016/j.jaut.2009.02.020

[77] R. H. Duerr, K. D. Taylor, S. R. Brant, et al., "A Genome-Wide Association Study Identifies IL23R as an Inflammatory Bowel Disease Gene," Science, Vol. 314, No. 5804, 2006, pp. 1461-1463. doi:10.1126/science.1135245

[78] J. Hampe, A. Franke, P. Rosenstiel, et al., "A Genome-Wide Association Scan of Nonsynonymous SNPs Identifies a Susceptibility Variant for Crohn Disease in ATG16L1," Nature Genetics, Vol. 39, No. 2, 2007, pp. 207-211. doi:10.1038/ng1954

[79] R. Sladek, G. Rocheleau, J. Rung, et al., "A GenomeWide Association Study Identifies Novel Risk Loci for Type 2 Diabetes," Nature, Vol. 445, No. 7130, 2007, pp.
881-885. doi: $10.1038 /$ nature 05616

[80] P. M. Gaffney, G. M. Kearns, K. B. Shark, et al., "A Genome-Wide Search for Susceptibility Genes in Human Systemic Lupus Erythematosus Sib-Pair Families," Proceedings of the National Academy of Sciences of the USA, 8 December 1998, pp. 14875-14879. doi:10.1073/pnas.95.25.14875

[81] E. Jorgenson and J. S. Witte, "A Gene-Centric Approach to Genome-Wide Association Studies," Nature Reviews Genetics, Vol. 7, No. 11, 2006, pp. 885-891. doi:10.1038/nrg1962

[82] S. Steer, V. Abkevich, A. Gutin, et al., "Genomic DNA Pooling for Whole-Genome Association Scans in Complex Disease: Empirical Demonstration of Efficacy in Rheumatoid Arthritis," Genes and Immunity, Vol. 8, No. 1, 2007, pp. 57-68. doi:10.1038/sj.gene.6364359

[83] X. Chu, C.-M. Pan, S.-X. Zhao, et al., "A Genome-Wide Association Study Identifies Two New Risk Loci for Graves' Disease," Nature Genetics, Vol. 43, No. 9, 2011, pp. 897-901. doi:10.1038/ng.898

[84] J. D. Cooper, M. J. Simmonds, N. M. Walker, et al., "Seven Newly Identified Loci for Autoimmune Thyroid Disease," Human Molecular Genetics, Vol. 21, No. 23, 2012. doi:10.1093/hmg/dds357

[85] M. Maierhaba, J. A. Zhang, Z. Y. Yu, et al., “Association of the Thyroglobulin Gene Polymorphism with Autoimmune Thyroid Disease in Chinese Population," Endocrine, Vol. 33, No. 3, 2008, pp. 294-299. doi:10.1007/s12020-008-9082-x 